\title{
Perubahan Status Gizi pada Anak dengan Leukemia Limfoblastik Akut Selama Terapi
}

\author{
Ronald Rompies, Shelvy P. Amelia, Stefanus Gunawan
}

\author{
Bagian Ilmu Kesehatan Anak, Fakultas Kedokteran Universitas Sam Ratulangi \\ RSUP Prof. Dr. R. D. Kandou, Manado - Indonesia \\ Email: ronald.rompies@gmail.com
}

\begin{abstract}
Nutritional status of children with acute lymphoblastic leukemia (ALL) can be altered by either chemotherapy or the leukemia itself. This study was aimed to evaluate the nutritional status alteration of ALL survivors who were treated at Estella Pediatric Cancer Care Manado. This was a cohort retrospective study involving survivors of ALL treated at Estella Pediatric Cancer Care Manado from January 2006 to December 2013. Data were collected from medical records, including body weight and height upon admission, end of induction, and at the beginning of maintenance as well as at the end of treatment. Nutritional status was assesed according to WHO 2006 and CDC 2000 growth charts. Data were analyzed using sign tests. The results showed that there were 31 ALL survivors consisted of 18 males and 13 females. Seventeen children were categorized as standard risk and 14 as high risk. A significant nutritional alteration was accrued during treatment, mainly in the induction phase $(p<0.05)$. These consisted of 1 child who had declined nutritional status, 15 children had no change of nutritional status, and 15 children had increased nutritional status. In conclusion, there is a significant alteration of nutritional status during ALL chemotherapy.
\end{abstract}

Keywords: treatment of ALL, nutritional status

\begin{abstract}
Abstrak: Status gizi pada anak dengan leukemia limfoblastik akut (LLA) dapat mengalami perubahan oleh karena kemoterapi atau penyakit leukemia itu sendiri. Penelitian ini bertujuan untuk mengevaluasi perubahan status gizi pada survivor LLA yang telah mendapat terapi di Pusat Kanker Anak Estella Manado. Jenis penelitian ialah kohort-retrospektif pada survivor LLA yang telah mendapatkan terapi di Pusat Kanker Anak Estella Manado dari bulan Januari 2006 sampai Desember 2013. Data dikumpulkan dari rekam medis, termasuk berat badan dan tinggi badan saat masuk rumah sakit, akhir fase induksi, saat awal pada fase maintenance, dan pada akhir dari terapi. Status gizi dinilai berdasarkan kurva WHO 2006 dan CDC 2000. Data kemudian dianalisis menggunakan test sign. Hasil penelitian mendapatkan 31 anak survivor LLA, terdiri dari 18 laki-laki dan 13 perempuan. Terdapat 17 anak yang masuk dalam kategori risiko standar dan 14 anak masuk dalam kategori risiko tinggi. Perubahan status gizi secara bermakna terjadi selama terapi, terutama pada fase induksi $(\mathrm{p}<0,05)$, yaitu pada akhir terapi didapatkan 1 anak dengan penurunan status gizi, 15 anak tanpa perubahan status gizi, dan 15 anak dengan peningkatan status gizi. Simpulan penelitian ini ialah terdapat perubahan yang bermakna pada status gizi selama pemberian kemoterapi LLA.
\end{abstract}

Kata kunci: terapi pada LLA, status gizi

\section{PENDAHULUAN}

Leukemia merupakan penyakit keganasan sel darah yang ditandai dengan adanya sel darah putih abnormal dalam sumsum tulang. Sekitar $90 \%$ dari keganas- an yang paling banyak didiagnosis pada anak ialah leukemia limfoblastik akut (LLA), ${ }^{1}$ yang mewakili lebih dari seperempat dari semua jenis kanker pada anak. Kejadian tahunan LLA di Amerika Serikat 
ialah 3,7-4,9 kasus per 100.000 anak usia 0-14 tahun, dengan puncak insidensi pada anak usia 2-5 tahun. ${ }^{2}$

Di Indonesia, melalui penelitian yang dilakukan di Rumah Sakit Cipto Mangunkusumo (RSCM), ditemukan bahwa leukemia merupakan jenis kanker yang paling banyak terjadi pada anak dengan usia di bawah 15 tahun (30-40\%). Berdasarkan data rekam medik RSUP Prof. Dr. R. D. Kandou Manado sepanjang tahun 20082012 jumlah anak yang menderita LLA ialah sekitar 60 anak yang rawat inap di bagian Pusat Kanker Anak Estella bagian Ilmu Kesehatan Anak RSUP Prof. Dr. R. D. Kandou. ${ }^{3}$

Nutrisi memainkan peran penting pada kondisi penyakit kronis. Malnutrisi pada anak dengan kanker dapat menurunkan angka toleransi kemoterapi dan peningkatan komplikasi. Beberapa penelitian menyebutkan bahwa malnutrisi dapat terjadi terutama pada beberapa bulan tahun pertama terapi intensif. ${ }^{4}$ Pada saat yang sama, kanker dan pengobatannya dapat memengaruhi asupan energi dan penggunaannya. Selama dan setelah pengobatan, anak dengan LLA akan mengalami kenaikan berat badan yang cukup besar. Penggunaan kortikosteroid jangka panjang, diet, dan kurangnya lathan fisik menyebabkan perubahan status gizi pada anak dengan LLA. Obesitas dapat menambah risiko menjadi lebih buruk pada kondisi penyakit kronis termasuk LLA. ${ }^{5}$

Berdasarkan latar belakang yang telah dipaparkan maka dilakukan penelitian ini yang bertujuan untuk mengetahui perubahan status gizi pada anak dengan LLA yang telah mendapatkan terapi di Pusat Kanker Anak Estella Bagian Ilmu Kesehatan Anak RSUP Prof. Dr. R. D. Kandou Manado.

\section{METODE PENELITIAN}

Jenis penelitian ini ialah deskriptif analitik dengan metode studi kohortretrospektif. Populasi dalam penelitian ini ialah data semua anak yang telah mendapatkan terapi di ruang Pusat Kanker Anak Estella Bagian Ilmu Kesehatan Anak RSUP Prof. Dr. R. D. Kandou Manado dari
Januari 2006 s/d Agustus 2013. Pada penelitian ini didapatkan sebanyak 31 data dari semua anak yang menderita LLA risiko standar dan risiko tinggi yang telah mendapatkan terapi di ruang Pusat Kanker Anak Estella bagian Ilmu Kesehatan Anak RSUP Prof. Dr. R. D. Kandou Manado. Kriteria inklusi ialah pasien yang data dan hasil rekam medisnya lengkap di ruang Pusat Kanker Anak Estella Bagian Ilmu Kesehatan Anak RSUP Prof. Dr. R. D. Kandou Manado dan pasien dengan LLA yang diterapi dengan protokol ALL Indonesia 2006.

Prosedur penelitian ini ialah mencari data berat badan, tinggi badan, serta usia pasien dengan LLA yang telah mendapatkan terapi di Pusat Kanker Anak Estella Bagian Ilmu Kesehatan Anak RSUP Prof. Dr. R. D. Kandou Manado dari bulan Januari 2006 s/d Agustus 2013. Data yang diperoleh dimasukkan pada kurva status gizi berdasarkan WHO 2006 dan CDC 2000 untuk mendapatkan status gizi pasien, kemudian data yang ada diuji dengan program SPSS versi 22 dengan analisis menggunakan sign test.

\section{HASIL PENELITIAN}

Berdasarkan data Pusat Kanker Anak Estella bagian Ilmu Kesehatan Anak RSUP Prof. Dr. R. D. Kandou Manado, didapatkan 31 anak yang masuk dalam kriteria inklusi.

Tabel 1 menampilkan karakteristik subyek penelitian. Frekuensi terbesar terjadi LLA terdapat pada usia 1-5 tahun, yaitu sebanyak 17 anak (54,8\%), diikuti usia 610 tahun sebanyak 12 anak $(38,7 \%)$, dan pada usia $>10$ tahun didapatkan sebanyak 2 anak $(6,5 \%)$. Jenis kelamin laki-laki (18 anak) lebih banyak daripada perempuan (13 anak) $(58,1 \%$ vs $41,9 \%)$. Risiko standar didapatkan sebanyak 17 anak $(54,8 \%)$ dan risiko tinggi sebanyak 14 anak $(45,2 \%)$.

Tabel 2 memperlihatkan bahwa frekuensi subyek pada saat awal diagnosis yang tersering ialah normal $(48,4 \%)$, diikuti gizi kurang $(35,5 \%)$, overweight $(9,7 \%)$, dan gizi buruk $(6,4 \%)$; tidak ditemukan $(0 \%)$ anak dengan status gizi obesitas. 
Tabel 1. Distribusi frekuensi sampel berdasarkan usia, jenis kelamin, dan resiko LLA

\begin{tabular}{lcc}
\hline & $\mathbf{n}$ & $\begin{array}{c}\text { Persentase } \\
(\mathbf{\%})\end{array}$ \\
\hline Usia & & \\
$<1$ tahun & 0 & 0 \\
1-5 tahun & 17 & 54,8 \\
6-10 tahun & 12 & 38,7 \\
$\quad>10$ tahun & 2 & 6,5 \\
Jenis kelamin & & \\
$\quad$ Laki-laki & 18 & 58,1 \\
$\quad$ Perempuan & 13 & 41,9 \\
Risiko LLA & & \\
$\quad$ Risiko standar & 17 & 54,8 \\
Risiko tinggi & 14 & 45,2 \\
\hline
\end{tabular}

Tabel 2. Status gizi berdasarkan berat badan menurut tinggi badan saat diagnosis

\begin{tabular}{ccc}
\hline Status Gizi & $\mathbf{n}$ & $\begin{array}{c}\text { Persentase } \\
(\mathbf{\%})\end{array}$ \\
\hline Obesitas & 0 & 0 \\
Overweight & 3 & 9,7 \\
Normal & 15 & 48,4 \\
Gizi kurang & 11 & 35,5 \\
Gizi buruk & 2 & 6,4 \\
\hline
\end{tabular}

Tabel 3 memperlihatkan frekuensi subyek pada akhir induksi dengan status gizi tersering ialah normal $(58,1 \%)$, diikuti gizi kurang $(22,6 \%)$, overweight $(9,7 \%)$, obesitas $(6,4 \%)$, dan gizi buruk $(3,2 \%)$.

Tabel 3. Status gizi berdasarkan berat badan menurut tinggi badan saat akhir induksi

\begin{tabular}{ccc}
\hline Status Gizi & $\mathbf{N}$ & $\begin{array}{c}\text { Persentase } \\
(\mathbf{\%})\end{array}$ \\
\hline Obesitas & 2 & 6,4 \\
Overweight & 3 & 9,7 \\
Normal & 18 & 58,1 \\
Gizi kurang & 7 & 22,6 \\
Gizi buruk & 1 & 3,2 \\
\hline
\end{tabular}

Tabel 4 memperlihatkan bahwa frekuensi subyek pada awal maintenance dengan status gizi tersering ialah normal $(67,7 \%)$, diikuti gizi kurang $(12,9 \%)$, serta obesitas dan overweight (masing-masing $9,7 \%$ ), sedangkan status gizi buruk tidak ditemukan $(0 \%)$.

Tabel 5 memperlihatkan bahwa frekuensi subyek pada akhir maintenance dengan status gizi tersering ialah normal $(77,5 \%)$, overweight $(16,1 \%)$, obesitas dan gizi kurang (masing-masing 3,2\%), sedangkan status gizi buruk tidak ditemukan $(0 \%)$.

Tabel 4. Status gizi berdasarkan berat badan menurut tinggi badan saat awal maintenance

\begin{tabular}{ccc}
\hline Status Gizi & n & $\begin{array}{c}\text { Persentase } \\
(\mathbf{\%})\end{array}$ \\
\hline Obesitas & 3 & 9,7 \\
Overweight & 3 & 9,7 \\
Normal & 21 & 67,7 \\
Gizi kurang & 4 & 12,9 \\
Gizi kuruk & 0 & 0 \\
\hline
\end{tabular}

Tabel 5. Status gizi berdasarkan berat badan menurut tinggi badan saat akhir maintenance

\begin{tabular}{ccc}
\hline Status Gizi & $\mathbf{n}$ & $\begin{array}{c}\text { Persentase } \\
(\mathbf{3 1})\end{array}$ \\
\hline Obesitas & 1 & 3,2 \\
Overweight & 5 & 16,1 \\
Normal & 24 & 77,5 \\
Gizi kurang & 1 & 3,2 \\
Gizi buruk & 0 & 0 \\
\hline
\end{tabular}

Untuk perubahan status gizi pada anak dengan LLA yang telah mendapatkan terapi di Pusat Kanker Anak Estella Bagian Ilmu Kesehatan Anak RSUP Prof. Dr. R. D. Kandou Manado dari Januari 2006-Agustus 2013, dilakukan analisis secara terpisah dengan menggunakan sign test.

Hasil uji perubahan status gizi setelah dilakukan induksi melalui sign test memperoleh nilai $\mathrm{p}=0,019$, yang mendapatkan 1 anak dengan penurunan status gizi, 22 anak dengan status gizi tetap, dan 8 anak dengan kenaikan status gizi. Hasil ini menyatakan adanya pengaruh induksi terhadap status gizi. Hasil uji perubahan status gizi setelah dilakukan maintenance melalui sign test memperoleh nilai $\mathrm{p}=0,274$, yang mendapatkan 4 anak dengan penurunan status gizi, 20 anak dengan status gizi tetap, dan 7 anak dengan kenaikan status gizi. Hasil ini menyatakan tidak terdapat pengaruh maintenance terhadap status gizi. Secara keseluruhan, hasil uji perubahan status gizi pada awal induksi sampai akhir maintenance melalui sign test memperoleh nilai $\mathrm{p}=0,006$, yang didapatkan 1 anak dengan 
penurunan status gizi, 15 anak dengan status gizi tetap, dan 15 anak dengan kenaikan status gizi. Hasil ini menyatakan adanya pengaruh induksi dan maintenance terhadap status gizi.

\section{BAHASAN}

Leukemia merupakan penyakit kanker yang terbanyak pada anak. Jenis LLA menempati peringkat paling atas di antara penyakit kanker yang dirawat di Departemen Ilmu Kesehatan Anak FKUI/RSCM dengan jumlah pasien baru 60-70 pasien per tahunnya. ${ }^{6}$ Pada penelitian ini yang dilakukan di ruang Pusat Kanker Anak Estella bagian Ilmu Kesehatan Anak RSUP Prof. Dr. R.D. Kandou terdapat 31 pasien survivors LLA yang memenuhi kriteria inklusi periode Januari 2006 s/d Agustus 2013.

Hasil analisis yang dilakukan memperlihatkan bahwa rerata usia anak dengan LLA dalam penelitian ini ialah 4 tahun dengan kelompok usia terbanyak 2-5 tahun, usia termuda 1 tahun, dan usia tertua 11 tahun. Hasil penelitian yang dilakukan di Rumah Sakit Kanker Dharmais juga menyebutkan bahwa kelompok usia $<5$ tahun merupakan kelompok usia dengan jumlah terbanyak. ${ }^{7}$ Selain hasil penelitian tersebut, sumber lain juga menyatakan bahwa insidensi puncak terjadi antara usia 2 hingga 5 tahun. ${ }^{8}$

Hasil analisis juga memperlihatkan bahwa jumlah pasien laki-laki lebih banyak yaitu $58,1 \%$ sedangkan perempuan $41,9 \%$. Untuk LLA dengan risiko standar memperlihatkan bahwa jumlah pasien laki-laki juga lebih banyak yaitu $58,8 \%$ sedangkan perempuan $41,2 \%$. Hasil yang sama juga terdapat pada LLA dengan risiko tinggi yaitu laki-laki $57,1 \%$ dan perempuan $42,9 \%$. Hasil penelitian lain di Rumah Sakit Kariadi Semarang juga menyebutkan hal yang sama yaitu ratio anak laki-laki lebih tinggi dari anak perempuan pada pasien LLA. ${ }^{9}$

Hasil analisis juga memperlihatkan bahwa pasien dengan risiko standar lebih tinggi persentasenya $(54,8 \%)$ dibandingkan dengan risiko tinggi $(45,2 \%)$. Penelitian lain yang dilakukan di Rumah Sakit Umum Dr. Soetomo Surabaya juga mendapatkan bahwa pasien dengan risiko standar lebih banyak dari resiko tinggi. ${ }^{10}$

Kanker dan terapinya dapat memengaruhi asupan dan pengeluaran energi melalui jalur kompleks. Pada penelitian ini, hasil analisis perubahan status gizi pada anak dengan LLA selama dan setelah mendapatkan terapi menunjukkan adanya peningkatan status gizi maupun status gizi yang tetap pada anak dengan LLA selama pengobatan baik risiko standar maupun risiko tinggi, dengan nilai $\mathrm{p}<0,05$ menunjukkan bahwa terdapat pengaruh bermakna selama terapi dengan perubahan status gizi pada anak yang telah mendapatkan terapi. Pada penelitian sebelumnya telah dilaporkan bahwa anak dengan kanker akan memiliki tanda dan gejala malnutrisi pada beberapa fase dalam perjalanan penyakitnya hingga 50-60\% kasus. Terdapat beberapa faktor yang menyebabkan malnutrisi pada anak dengan kanker, antara lain: 1) faktor spesifik untuk tumor; 2) faktor yang berhubungan dengan pasien; dan 3) faktor yang berhubungan dengan pengobatan. ${ }^{11}$ Pada negara dengan pendapatan besar tantangan survivors LLA lebih besar untuk menjadi overweight atau obesitas. Sebaliknya, pada negara dengan pendapatan menengah maupun rendah banyak dilaporkan bahwa survivors LLA yang mengalami malnutrisi lebih besar dengan persentase angka kejadian LLA yang besar pula. ${ }^{5}$

Suatu penelitian meta-analisis mendukung gagasan bahwa selama dan setelah pengobatan pasien di bawah protokol modern yang tidak menggunakan Cranial Radiation Theraphy (CRT) akan mengalami kenaikan berat badan yang cukup besar. Selain itu, dalam penelitian tersebut dinyatakan bahwa kenaikan berat badan pada pasien dengan LLA lebih banyak terjadi selama terapi awal dan kemudian dapat meningkat lagi selama fase maintenance dalam terapi. Survivors LLA memiliki risiko tinggi yang bermakna untuk terjadinya obesitas tetapi tanpa diketahui waktu pasti kapan dimulainya peningkatan berat badan. Kebanyakan pasien 
dengan LLA tidak dapat kembali pada berat badan awal sebelum menjalani terapi dan secara konsisten meningkat menjadi overweight atau obesitas sampai akhir terapi. Kortikosteroid seperti diketahui berperan mengatur asupan, penyimpanan, dan pergerakan energi. Selain itu, kemoterapi lain seperti vincristine dapat juga berperan dalam peningkatan berat badan dengan merusak fungsi kardiovaskuler dan kekuatan otot sehingga selanjutnya dapat mengurangi tingkat aktifitas fisik. ${ }^{12}$

Penggunaan kortikosteroid jangka panjang telah menunjukkan efek peningkatan asupan energi dan persentase lemak tubuh pada anak dengan LLA. Pengurangan dosis kortikosteroid selama maintenance dapat mengurangi angka peningkatan berat badan selama periode terapi. Anak dengan LLA memiliki risiko kegemukan atau obesitas di awal pengobatan dan kemungkinan terus meningkat selama pengobatan sampai seterusnya. Berdasarkan bukti terbaru pengobatan kanker, menunjukkan bahwa anakanak mengalami kesulitan mengembalikan dari kebiasaan makan yang tidak sehat dan perilaku menetap setelah selesai pengobatan. ${ }^{13}$

Penderita kanker pada masa kanakkanak 7 kali lebih mungkin meninggal karena penyakit jantung daripada populasi umum. Risiko untuk berkembang menjadi penyakit jantung lebih bermakna meningkat. Hal ini terkait faktor-faktor seperti hipertensi, dislipidemia, resistensi insulin atau diabetes, dan obesitas di usia muda. ${ }^{14}$ Obesitas, hipertensi dan sindrom metabolik banyak dilaporkan terjadi di antara survivors LLA. Obesitas menambah besar risiko kondisi penyakit kronis yang sudah dialami oleh penderita kanker sejak masa kanak-kanak. Studi sebelumnya menunjukkan bahwa semakin muda usia saat terdiagnosis LLA berhubungan dengan risiko peningkatan indeks massa tubuh (IMT) selama terapi. Oleh karena itu, mengidentifikasi kondisi obesitas dan faktor risiko yang disebabkan oleh obesitas merupakan prioritas utama untuk meningkatkan kesehatan jangka panjang dari masa kanak-kanak pada penderita kanker. ${ }^{15}$
Pemberian terapi pada anak dengan LLA memengaruhi perubahan status gizi. Hal ini juga terjadi pada anak-anak yang telah mendapatkan terapi di Pusat Kanker Anak Estella Bagian Ilmu Kesehatan Anak RSUP Prof. Dr. R. D. Kandou, yaitu terdapat perubahan bermakna dari status gizi anak setelah menjalani terapi yaitu terjadi kenaikan status gizi pada anak setelah menjalani terapi.

Keterbatasan dalam penelitian ini ialah tidak adanya beberapa data pasien LLA serta pada beberapa data pasien di rekam medik tidak mencantumkan data berat badan dan tinggi badan pasien selama pengobatan.

\section{SIMPULAN}

Pada anak-anak yang mendapatkan terapi di Pusat Kanker Anak Estella Bagian Ilmu Kesehatan Anak RSUP Prof. Dr. R. D. Kandou, terdapat perubahan status gizi yang bermakna.

\section{Konflik Kepentingan}

Penulis menyatakan tidak terdapat konflik kepentingan dalam studi ini.

\section{DAFTAR PUSTAKA}

1. Hunger SP, Lu X, Devidas M, Camitta BM, Gaynon PS, Winick NJ, et al. Improved survival for children and adolescents with acute lympho-blastic leukemia between 1990 and 2005: A report from children's oncology group. J Clin Oncol. 2012;30:1663-9.

2. Ribera JM, Oriol A. Acute lymphoblastic leukemia in adolescents and young adults. Hematol Oncol Clin North Am. 2009;23(5):1033-42, vi.

3. Simanjorang C, Kodim N, Tehuteru E. Perbedaan kesintasan 5 tahun pasien leukemia limfoblastik akut dan leukemia mieloblastik akut pada anak di Rumah Sakit Kanker "Dharmais." Jakarta: FKM UI, 2013; p. 1997-2008.

4. Gandhi LV, Shreedhara AK, Rau ATK, Rau A. nutritional assessment of children with hematological malignancies and their subsequent tolerance to chemotherapy. The Ochsner Journal. 2012; 12:197-201. 
5. Bar RD. Nutritional status in children with cancer: before, during and after therapy. Indian J Cancer 2015;52: 173-5.

6. Sari TT, Windiastuti E, Cempako GR, Devaera Y. Prognosis leukemia limfoblastik akut pada anak obes. Sari Pediatri. 2011;12(1):59.

7. Tehuteru ES. Gambaran tingkat remisi pada leukemia limfoblastik akut setelah fase induksi di bangsal kanker anak RS Kanker Dharmais. Indonesian Journal of Cancer. 2011; 5(4):160.

8. Meadow R, Newell S. Lecture Notes Pediatrica (7th ed). In: Safitri A, editor. Jakarta: Penerbit Erlangga, 2005; p. 223.

9. Nency YM. Perbedaan kebutuhan transfusi darah selama fase induksi pada leukemia limfoblastik akut. Sari Pediatri. 2011;3(4):272.

10. Widiaskara IM, Purnomo B, Ugrasena IDG, Ratwita M. Luaran pengo-batan fase induksi pasien leukemia limfoblastik akut pada anak di Rumah Sakit Umum Dr. Soetomo Surabaya. Sari Pediatri. 2010;12(2): 130.

11. Alcázar AM, Núñez-Enríquez JC, García-
Ruiz CA, Fajardo-Gutierrez C, MejíaAranguré JM. Alterations of nutritional status in childhood acute leukemia. IntechOpen, 2013; p. 277-96.

12. Zang FF, Liu S, Chung M, Kelly MJ. Growth patterns during and after treatment in patients with pediatric ALL: a metaanalysis. Pediatric Blood Cancer. 2015;62:1452-60.

13. Tan SY, Poh BK, Nadrah MH, Jannah NA, Rahman J, Ismail MN. Nutritional status and dietary intake of children with acute leukaemia during induction or consolidation chemotherapy. J Hum Nutr Diet. 2013;26 (Suppl. 1);23-33.

14. Zhang FF, Parsons SK. Obesity in childhood cancer survivors: call for early weight management. Ameri-can Society for Nutrition. Adv Nutr 2015;6:611-9.

15. Esbenshade AJ, Simmons JH, Koyama T, Koehler E, Whitlock JA, Friedman DL. Body mass index and blood pressure change over the course of treatment of pediatric acute lymphoblastic leukemia. Pediatr Blood Cancer. 2011;56(3):3728. 